\title{
Hypercalcaemia Caused by Sunflower Seeds and Calcium Carbonate Supplements
}

\author{
Iqra Patoli ${ }^{1}$, Mehrunissa Kazim $^{2}$, Saad Bin Jamil ${ }^{3}$, Syed Hassan Abbas ${ }^{1}$ \\ ${ }^{1}$ Department of Internal Medicine, St. Mary's Hospital, Waterbury, CT, USA \\ ${ }^{2}$ Department of Internal Medicine, Holyoke Health Center, Holyoke, MA, USA \\ ${ }^{3}$ Thomas Jefferson University, Philadelphia, PA, USA
}

Received: 22/08/2021

Accepted: $29 / 08 / 2021$

Published: $13 / 10 / 2021$

How to cite this article: Patoli I, Kazim M, Jamil SB, Abbas SH. Hypercalcaemia caused by sunflower seeds and calcium carbonate supplements. EJCRIM 2021;8: doi:10.12890/2021_002845.

Conflicts of Interests: The authors declare there are no competing interests.

This article is licensed under a Commons Attribution Non-Commercial 4.0 License

\section{ABSTRACT}

Introduction: Hypercalcaemia is commonly associated with malignancy or endocrinological disorders. However, sometimes it can occur due to increased oral intake of calcium. We present an interesting case of hypercalcaemia due to ingestion of sunflower seeds and calcium carbonate supplements.

Case Description: We present the case of a 53-year-old man with history of T-cell lymphoma and gastroesophageal reflux disease who was brought to the emergency room due to altered mental status, nausea, vomiting and abdominal pain. His calcium level was 3.30 mmol/I (normal value 2.23-2.58 mmol/l). Imaging studies were unremarkable. The patient was hydrated with normal saline and calcium levels improved. Once he was more coherent, he disclosed that he had consumed significant amounts of sunflower seeds and calcium carbonate supplements, which were considered to be the cause of his hypercalcaemia.

Conclusion: Hypercalcaemia is common and can lead to critical illness. Although hypercalcaemia is frequently associated with endocrinological disorders, sometimes the presentation is secondary to increased intake. The consumption of sunflower seeds and antacids containing calcium carbonate can cause symptomatic hypercalcaemia. It is important to recognize rare causes of hypercalcaemia in order to treat it in a timely manner and prevent recurrence.

\section{LEARNING POINTS}

- Hypercalcaemia can occur due to excessive intake of sunflower seeds and calcium carbonate supplements.

- Hydration and cessation of oral supplements can result in rapid reversal of hypercalcaemia.

- It is important to obtain a complete history in order to determine the aetiology of hypercalcaemia.

\section{KEYWORDS}

Hypercalcemia, calcium carbonate supplements, sunflower seeds

\section{INTRODUCTION}

Hypercalcaemia is a common condition and usually secondary to hyperparathyroidism or malignancy ${ }^{[1]}$. However, there are several other causes such as thyroid disorders, supplement intake and rheumatological disease. The relationship between hypercalcaemia and calcium carbonate supplements is well reported in the literature but its association with sunflower seeds has not been fully studied. Sunflower seeds 
and sprouts have high concentrations of vitamin A in addition to high levels of calcium, potassium, zinc and minerals ${ }^{[2]}$. Hence, sunflower seeds can cause hypercalcaemia if taken in large amounts.

We present an interesting case of hypercalcaemia secondary to excessive intake of calcium carbonate supplements and sunflower seeds.

\section{CASE DESCRIPTION}

A 53-year-old man with a past medical history significant for gastroesophageal reflux disease and T-cell lymphoma was brought to the emergency room due to progressively worsening confusion for 1 day. The patient also had associated nausea, vomiting and abdominal pain. The medication list provided by his family included atorvastatin, omeprazole, evolucumab and paroxetine.

On examination, the patient's vital signs were stable; blood pressure was $154 / 74 \mathrm{mmHg}$, pulse was 68 beats/min, respiratory rate was 20 , temperature was $36.9^{\circ} \mathrm{C}$, and oxygen saturation was $95 \%$ on room air. Neurological examination was limited due to altered mental status, and there were no signs of meningeal irritation. The rest of the examination was normal.

Relevant laboratory results were: leukocyte count of $15.5 \times 10^{\%} /$ I (normal value $\left.4.0-10.5 \times 10^{9} / \mathrm{I}\right)$, serum calcium of $3.30 \mathrm{mmol} / \mathrm{I}$ (normal value 2.23-2.58 mmol/I), serum albumin of $47.00 \mathrm{~g} / \mathrm{l}$ (normal value 35.00-50.00 g/l), 25-hydroxyvitamin D of $169.73 \mathrm{nmol} / \mathrm{I}$ (normal value 74.88 $249.60 \mathrm{ng} / \mathrm{ml}$ ), 1,25-dihydroxyvitamin D of $64.80 \mathrm{pmol} / \mathrm{l}$ (normal value $48.00-189.6 \mathrm{pmol} / \mathrm{l}$ ) and parathyroid hormone of $0.731 \mathrm{pmol} / \mathrm{I}$ (normal value 1.272-9.331 pmol/I). Parathyroid hormone-related protein was also within the normal range. Computed tomography (CT) of the head did not show any intracranial bleeding or stroke. CT of the abdomen and pelvis did not show any clear source of intra-abdominal aetiology. Magnetic resonance imaging (MRI) of the brain did not reveal any abnormality. A lumbar puncture was also performed, and the results were unremarkable.

The patient was initially given broad-spectrum antibiotics and normal saline. He became agitated and required sedatives. A critical care consultant evaluated the patient in the emergency room, but admission was deferred to medicine service and the patient was continued on aggressive intravenous fluids. Antibiotics were discontinued after lumbar puncture results were received and as per the infectious disease consultant's recommendations. Calcium levels decreased towards the normal range and the patient's mental status gradually improved, eventually normalizing. Once coherent, the patient mentioned he had eaten significant amounts of sunflower seeds for the last few days to relieve constipation, sometimes consuming up to 1 cup a day. Initially, he denied using calcium carbonate supplements, but later said he took them for gastrointestinal reflux disease. He was counselled regarding avoiding excessive use of sunflower seeds and calcium carbonate supplements due to the risk of hypercalcaemia. He was discharged in a stable condition upon clinical improvement.

\section{DISCUSSION}

Hypercalcaemia is a common disorder frequently occurring secondary to hyperparathyroidism and malignancy. Some other causes of hypercalcaemia include vitamin A toxicity, vitamin D toxicity, various drugs, Paget's disease, granulomatous diseases, and excessive intake of calcium supplements.

Hypercalcaemia can present with variable signs and symptoms depending on the level of hypercalcaemia, such as altered mental status, abdominal pain, constipation, depressed mood and vomiting. However, it is often asymptomatic and is most commonly detected on laboratory testing ${ }^{[1]}$. In our case, the patient had altered mental status and constipation. Severe hypercalcaemia can lead to significant morbidity and mortality. Acute hypercalcaemia can rarely be life threatening ${ }^{[3]}$.

Calcium carbonate supplements have been long associated with milk alkali syndrome, which presents as hypercalcaemia, renal failure and metabolic alkalosis. The association between sunflower seeds and hypercalcaemia has not yet been clearly established. Sunflower seeds have high concentrations of calcium as well as vitamin A. Hence, we believe sunflower seeds can lead to hypercalcaemia because they have a high calcium content and are a source of vitamin A, which can cause hypercalcaemia. T-cell lymphoma is a rare cause of hypercalcaemia. Our patient had several risk factors for hypercalcaemia such as excessive intake of calcium carbonate supplements, consumption of sunflower seeds, and a history of T-cell lymphoma. However, we believe that the primary cause of hypercalcaemia in our patient was ingestion of sunflower seeds in combination with calcium-containing supplements. Calcium carbonate supplements can lead to hypercalcaemia on their own, however, our patient did not meet the criteria of milk alkali syndrome as laboratory results did not suggest renal failure or metabolic alkalosis. We believe that this further indicates that a combination of sunflower seeds and calcium carbonate supplementation caused the hypercalcaemia. We do not believe that T-cell lymphoma was a factor due to the acuity of presentation, presence of alternative aetiologies, rapid reversal and because the patient's disease was in remission.

The severity of hypercalcaemia is determined by the calcium level. The levels are as follows: mild levels range from 2.63 to $2.98 \mathrm{mmol} / \mathrm{l}$, moderate ranges from 3.00 to $3.48 \mathrm{mmol} / \mathrm{l}$, and severe levels from 3.50 to $4.00 \mathrm{mmol} / \mathrm{I}^{[4]}$. Our patient had a moderate level of hypercalcaemia. Management depends on the degree of hypercalcaemia and symptoms. The main treatments include aggressive intravenous hydration with fluids, steroids, bisphosphonate therapy and sometimes diuresis. If the calcium levels are very high, dialysis may be necessary to quickly 


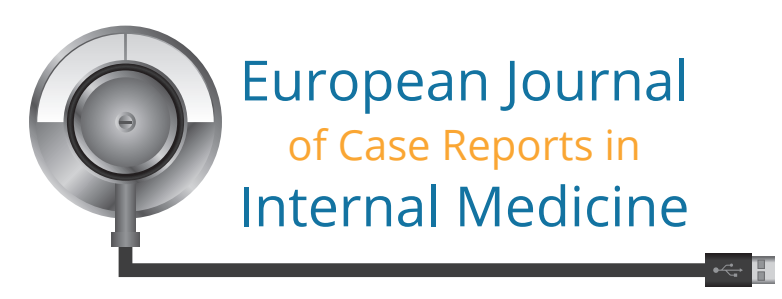

bring down calcium levels. As our patient's moderate hypercalcaemia responded rapidly to aggressive intravenous hydration and cessation of supplements, other treatments were not explored.

The aetiology of hypercalcaemia in our patient was initially unclear. Once he was hydrated, his mental status improved and he mentioned two potential causes of hypercalcaemia. This highlights the importance of comprehensive history-taking and follow-up for accurate diagnosis. Obtaining a proper history is also very important for management ${ }^{[5]}$.

Hypercalcaemia is a common medical condition and can be life threatening. It is important to take a proper history and recognize rare causes when the aetiology is uncertain. Early diagnosis and intervention can prevent long-term morbidity and mortality.

\section{REFERENCES}

1. Turner JJO. Hypercalcaemia - presentation and management. Clin Med (Lond) 2017 Jun;17(3):270-273. doi: 10.7861/clinmedicine.17-3-270.

2. Guo S, Ge Y, Na Jom K. A review of phytochemistry, metabolite changes, and medicinal uses of the common sunflower seed and sprouts (Helianthus annuus L.). Chem Cent J 2017 Sep 29;11(1):95. doi: 10.1186/s13065-017-0328-7.

3. Basso SM, Lumachi F, Nascimben F, Luisetto G, Camozzi V. Treatment of acute hypercalcemia. Med Chem 2012 Jul;8(4):564-568. doi: 10.2174/157340612801216382.

4. Sadiq NM, Naganathan S, Badireddy M. Hypercalcemia. [Updated August 11, 2021]. In: StatPearls [Internet]. Treasure Island (FL): StatPearls Publishing; 2021 Jan-. Available from: https://www.ncbi.nlm.nih.gov/books/NBK430714/

5. $\quad$ Kassirer J, Wong J, Kopelman R. Learning clinical reasoning. 2. Baltimore: Lippincott Williams \& Wilkins; 2010. 